\title{
Gummatous neurosyphilis in an elderly patient in the Australian outback: a case report
}

\author{
Nilesh Anand Devanand* ${ }^{*}$ and Krishnaswamy Sundararajan (1)
}

\begin{abstract}
Introduction: Neurosyphilis is an infection caused by the spirochete Treponema pallidum, which causes infiltration and thickening of brain meninges. Despite being an Old World disease, the rates of infection continue to rise. This clinical challenge involves early and accurate diagnosis, as neurosyphilis masquerades with various clinical symptoms and is often missed during initial presentation to the hospital. A comprehensive history and clinical examination are essential to detect suspicious cases early for further cerebrospinal fluid examination and neuroimaging. Patients treated with benzylpenicillin for a specific duration often show promising clinical and cognitive improvement, thus emphasizing the need for constant vigilance in our day-to-day practice.
\end{abstract}

Case presentation: A 77-year-old Caucasian gentleman presented to our hospital repeatedly with multiple episodes of presyncope and cognitive impairment. He also demonstrated bilateral deafness, tabes dorsalis, and left sixth cranial nerve palsy. His cerebrospinal fluid examination showed a nonreactive venereal disease research laboratory test, and magnetic resonance imaging of the brain revealed a gumma.

Conclusion: The diagnosis of neurosyphilis in the elderly requires a combination of clinical vigilance and a high index of suspicion, along with multimodal investigations, including cerebrospinal fluid examination and brain imaging.

Keywords: Syphilis, Neurosyphilis, Gumma, CSF VDRL

\section{Introduction}

Syphilis is a sexually transmitted disease that has been present for centuries. It is caused by the spirochete Treponema pallidum and is transmitted horizontally through sexual contact or vertically from mother to baby. Its disease is broadly categorized into four stages: the primary stage, characterized by the development of a painless ulcer known as a chancre on the genitalia; the secondary stage, often seen with disseminated disease, which predominates with cutaneous manifestations; and a late early and late latent phase, whereby obvious clinical symptoms have resolved, and laboratory investigations are key to making a diagnosis. The tertiary stage is characterized by the presence of gumma, a rubbery

\footnotetext{
*Correspondence: drnileshanand@gmail.com Intensive Care Unit, Level 4, Royal Adelaide Hospital, Port Road, Adelaide, SA 5000, Australia
}

noncontractile tumor that mainly presents on the skin but can occur in other organs, including the brain. In Australia, the national update on sexually transmitted diseases demonstrated an increase of $146 \%$ in syphilis notifications from 2014 to 2018, predominantly among women [1].

Neurosyphilis, often a late sequelae of untreated syphilis, presents with multiple neurocognitive signs and symptoms, including syncope, memory loss, dementia, vision and hearing impairment, cranial nerve involvement, peripheral neuropathy, and, rarely, cerebral gummas. The variety of clinical presentations combined with the lack of a gold standard test has made the diagnosis often challenging. It has raised many controversies surrounding the utility of cerebrospinal fluid (CSF) assays for disease confirmation. So far, there are limited Australian data on neurosyphilis, especially with cerebral gummas.

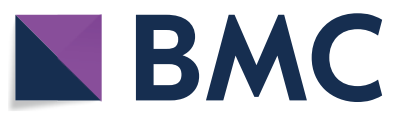

(c) The Author(s) 2021. Open Access This article is licensed under a Creative Commons Attribution 4.0 International License, which permits use, sharing, adaptation, distribution and reproduction in any medium or format, as long as you give appropriate credit to the original author(s) and the source, provide a link to the Creative Commons licence, and indicate if changes were made. The images or other third party material in this article are included in the article's Creative Commons licence, unless indicated otherwise in a credit line to the material. If material is not included in the article's Creative Commons licence and your intended use is not permitted by statutory regulation or exceeds the permitted use, you will need to obtain permission directly from the copyright holder. To view a copy of this licence, visit http://creativecommons.org/licenses/by/4.0/. The Creative Commons Public Domain Dedication waiver (http://creativeco mmons.org/publicdomain/zero/1.0/) applies to the data made available in this article, unless otherwise stated in a credit line to the data. 
Neurosyphilis is often diagnosed with a combination of clinical and CSF findings. However, the interplay between neuroinvasion and inflammatory markers is complex. While a CSF venereal disease research laboratory (VDRL) test is thought to be highly specific, its sensitivity is debatable, with most published papers in the current era citing a sensitivity in the range of 50-60\% [2]. Additionally, CSF pleocytosis and elevated protein counts are often ambiguous in their diagnostic value and do not add to the overall disease detection.

\section{Case presentation}

Our patient is a 77-year-old frail gentleman with type 2 diabetes mellitus on oral hypoglycemic medications who lives with his daughter, requiring support with daily living activities. His past medical history is significant for hypertension, chronic kidney disease, and gout. He is a former smoker and denies recent alcoholism. Prior to his monogamous relationship with his partner, he vaguely recalls having unprotected sexual relations in his teens, almost 50 years ago. He denies being treated for any sexual transmitted diseases (STDs), and confirms nil significant family history for STDs.

He mobilizes with a four-wheel walker, and presented to the hospital with vomiting, presyncope, and an unwitnessed fall without loss of consciousness.

He reports almost daily postural dizziness and has had several short admissions in the past for recurrent presyncope and falls. He denies other systemic complaints.

His history is significant for bilateral hearing impairment, previously attributed to a vestibular disease and a possible past syphilis infection which remains unknown within the local STD registry. It is uncertain whether treatment was ever commenced. A baseline VDRL test was unavailable.

On examination, his vitals were stable with demonstrable postural hypotension. A neurological examination demonstrated a right eye relative afferent pupillary defect, left eye abducens nerve palsy, and a high stepping gait of the right foot. A review of his symptoms was otherwise unremarkable, except for a prolonged PR interval (200-220 milliseconds) on his electrocardiogram (ECG).

His routine blood biochemistry was as expected, and syphilis serology detected Treponema pallidum particle agglutination (TPPA) as well as previously undetected rapid plasma reagin (RPR) titers, giving rise to uncertainty as to whether the syphilis infection was prior or current. A lumbar puncture displayed clear CSF within normal pressures with a high protein count of $2.59 \mathrm{mg} /$ $\mathrm{dl}$ and an elevated CSF white cell count at $12 \times 10^{6} / \mathrm{L}$ (Table 1). In addition, the CSF syphilis nucleic acid antigen (NAA) test was negative, CSF fluorescent treponemal
Table 1 Results of cerebrospinal fluid (CSF) test prior to commencement of antibiotics

\begin{tabular}{|c|c|c|}
\hline CSF test & Results & Reference range \\
\hline \multicolumn{3}{|l|}{ Biochemistry } \\
\hline Protein & $2.59 \mathrm{~g} / \mathrm{L}$ & $0.15-0.45 \mathrm{~g} / \mathrm{L}$ \\
\hline Glucose & $4.6 \mathrm{mmol} / \mathrm{L}$ & $2.7-4.2 \mathrm{mmol} / \mathrm{L}$ \\
\hline \multicolumn{3}{|l|}{ CSF examination } \\
\hline Description & Clear and colorless & \\
\hline \multicolumn{3}{|l|}{ Microscopy } \\
\hline Leukocytes $\left(\times 10^{6} / \mathrm{L}\right)$ & 12 & $<5 \times 10^{6} / \mathrm{L}$ \\
\hline Polymorphs (\%) & 4 & \\
\hline Mononuclear cells (\%) & 96 & \\
\hline Erythrocytes $\left(\times 10^{6} / \mathrm{L}\right)$ & 4 & $<5 \times 10^{6} / \mathrm{L}$ \\
\hline India Ink & No Cryptococcus seen & \\
\hline Gram stain & No organism seen & \\
\hline Culture & No growth after 48 hours & \\
\hline \multicolumn{3}{|l|}{ Syphilis serology } \\
\hline CSF FTA & Minimally reactive & \\
\hline CSF TPPA & Nonreactive & \\
\hline CSF VDRL & Nonreactive & \\
\hline
\end{tabular}

CSF: Cerebrospinal fluid, FTA: Fluorescent Treponemal Antibody absorption test, TPPA: Treponemal pallidum particle agglutination assay, VDRL:Venereal Disease Research Laboratory test

antibody (FTA) was minimally reactive, and CSF TPPA and VDRL were both nonreactive.

His echocardiogram revealed normal ventricular function without valvular pathologies. Alarmingly, an inpatient Holter test detected a 6 -second sinus pause that was emergently addressed with the insertion of a pacemaker within 24 hours and a brief postprocedural cardiac care unit admission for observation.

A non-contrast computerized tomography (CT) scan of the brain showed thickening of the meninges at the left clivus, resembling a meningioma, and this was further followed up by a magnetic resonance imaging (MRI) of the brain. The MRI reported similar findings, with the addition of possible chronic mastoiditis. As a consequence of this significant finding, a multidisciplinary collaboration between geriatrics, neurosurgery, and radiology was undertaken. It was concluded beyond reasonable doubt that the MRI was consistent with a radiological diagnosis of gumma (Fig. 1). With clinical consensus, the final diagnosis of gummatous neurosyphilis was made.

A cognitive assessment was attempted while the investigation (pre-treatment) was ongoing but was limited by hearing and vision impairment. A baseline Mini-Mental State Examination (MMSE) was attempted but was prematurely stopped because of the patient's poor comprehension of the examination questions. An assessment of delirium was also limited for the same reason. 


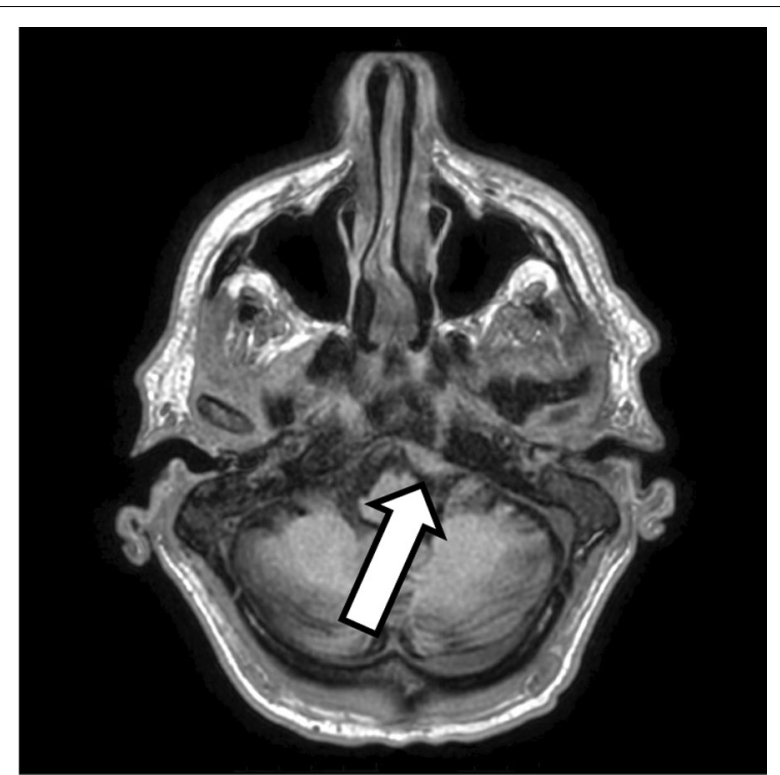

Fig. 1 T1-weighted brain MRI demonstrating a thickening of the meninges that was initially considered a meningioma but subsequently re-diagnosed as a gumma (left, arrow)
He was commenced on 1.8 million units of intravenous benzylpenicillin, 4-hourly for 15 days, and was sent to the Geriatric Medical Unit for ongoing care and physiotherapy. On completing his antibiotic regime, he made a satisfactory recovery-notably, with an improvement in his cognition from severe to mild cognitive impairment (MMSE 22/30) post-treatment and an appreciative reduction in the size of his gumma on the repeat MRI scan (Fig. 2).

Despite negative CSF Treponema pallidum serology, which is known to have low sensitivity and may thus contribute to false negative cases, the poignant history of bilateral deafness, the presence of a sixth cranial nerve pathology, an Argyll Robertson pupil, a tabes dorsalis gait, and an extremely high CSF protein with a gumma on the brain MRI collectively diagnosed this patient as having gummatous neurosyphilis.

\section{Discussion}

Neurosyphilis, an infectious complication of the central nervous system caused by the spirochete Treponema pallidum continues to increase in prevalence [3] but remains challenging to diagnose quickly and accurately [4] because of multiple non-specific symptoms that can manifest at different stages of the disease.

In the early stages, infiltration into the CSF, meninges, and blood vessels is often seen. The late presentation

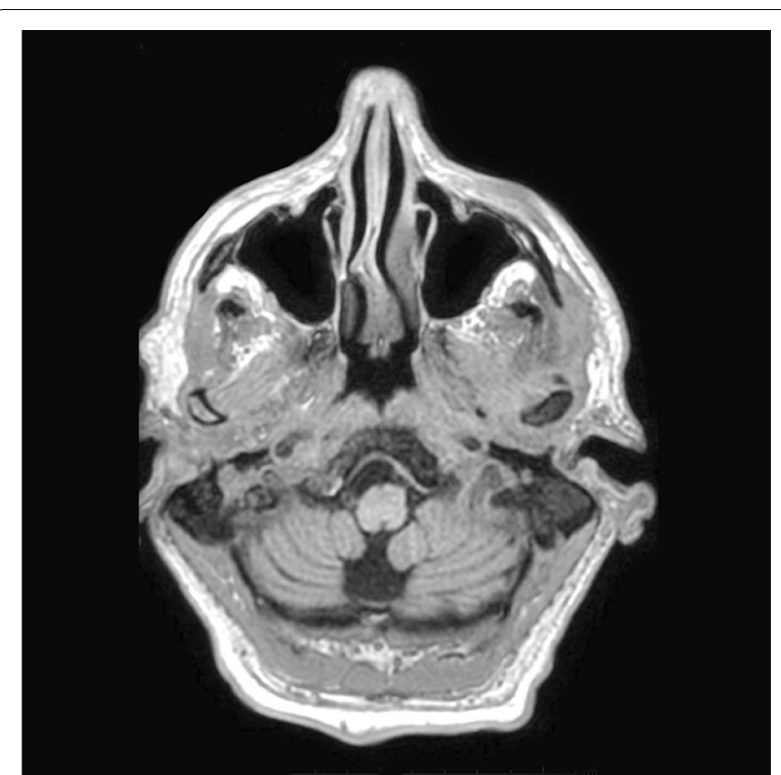

Fig. 2 Following therapy with intravenous benzylpenicillin, a follow-up brain MRI 3 months later displayed a pronounced reduction in the size of the gumma (right)

usually involves brain parenchyma and the spinal cord, necessitating the need for CSF examination [5].

Neurosyphilis often masquerades with non-specific symptoms, and unclear laboratory investigations frequently lead to delayed and inaccurate diagnosis. Especially in elderly patients because of confounding influences and age-related cognitive decline.

The current criteria for diagnosing neurosyphilis depends on a combination of reactive serological test results including CSF antibody and TPPA test, white cell and protein count, as well as a reactive CSF-VDRL with or without clinical symptoms. Suspicion of neurosyphilis arises when the CSF white blood cell count is higher than $20 \times 10^{6}$ cells/L or a CSF VDRL test result is reactive [6].

Neurosyphilis should also be considered in patients presenting with neuropsychiatry symptoms. Including neuroimaging as a mode of investigation often helps to elucidate dural thickening, as the disease can affect the meninges [7].

\section{Conclusion}

While neurosyphilis remains a disease of the Old World, it continues to be prevalent. This case demonstrates that, with a high index of clinical suspicion, coupled with timely investigations, accurate interpretation, and targeted therapy in a multidisciplinary approach, we could significantly reduce the burden of this 
indolent disease and improve patient care in resourceconstrained environments.

\section{Abbreviations}

CSF: Cerebrospinal fluid; FTA: Fluorescent treponemal antibody; MMSE: MiniMental State Examination; NAA: Nucleic acid antigen; RAPD: Relative afferent pupillary defect; RPR: Rapid plasma reagin; TPPA: Treponema pallidum particle agglutination; VDRL: Venereal disease research laboratory.

\section{Acknowledgements}

Dr. Xin Yi Er (Basic Physician Trainee, Royal Darwin Hospital).

\section{Authors' contributions}

NAD obtained clinical information about the patient, performed the literature search, and prepared the manuscript. KS assisted with the literature search, edited the manuscript, and provided intellectual input and technical expertise in finalizing the manuscript. All authors read and approved the final manuscript.

\section{Funding}

No funding sources to declare.

Availability of data and materials

Data are available on request.

\section{Declarations}

\section{Ethics approval and consent to participate}

Our manuscript does not report on an investigational therapy, nor does it involve the use of any animal or human data or tissue in any experiment; hence, this section related to ethics approval does not apply to our submission. Ethics committee approval to produce a case report in the presence of written consent from the patient was, therefore, deemed inapplicable.

\section{Consent for publication}

Written informed consent was obtained from the patient for publication of this case report and any accompanying images. A copy of the written consent is available for review by the Editor-in-Chief of this journal.

\section{Competing interests}

Both authors declares no competing interests.

Received: 26 April 2021 Accepted: 18 October 2021

Published online: 09 November 2021

\section{References}

1. Kirby Institute. National update on HIV, viral hepatitis and sexually transmissible infections in Australia: 2009-2018. Sydney: Kirby Institute, UNSW Sydney, 2018. https://kirby.unsw.edu.au/sites/default/files/kirby/report/ National-update-on-HIV-viral-hepatitis-and-STIs-2009-2018.pdf.

2. Musher DM. Editorial commentary: polymerase chain reaction for the tpp47 gene: a new test for neurosyphilis. Clin Infect Dis. 2016;63(9):1187-8.

3. Blazekovic A, Ozretic D. Neurosyphilis: the shape of a rising threat. Int J Infect Dis. 2018:76:1-3.

4. Rodrigues RP, Correia N, Lopes AV. Neurosyphilis with optical involvement in an immunocompetent patient: a case report. Int Med Case Rep J. 2012;5:5-11.

5. Mattei PL, Beachkofsky TM, Gilson RT, Wisco OJ. Syphilis: a reemerging infection. Am Fam Physician. 2012;86(5):433-40.

6. Zhang YQ, Huang M, Jia XY, Zou YF, Chen D. A clinical study of new cases of parenchymal neurosyphilis: has tabes dorsalis disappeared or been missed? J Neuropsychiatry Clin Neurosci. 2015;27(1):17-21.

7. Júnior RM, de Caçador AT, Biasutti C, Gonçalves GAM, Ferreira Júnior GCU. Teaching neuroimages: skull and dural lesions in neurosyphilis. Neurology. 2016;87(12):129-30.

\section{Publisher's Note}

Springer Nature remains neutral with regard to jurisdictional claims in published maps and institutional affiliations.
Ready to submit your research? Choose BMC and benefit from:

- fast, convenient online submission

- thorough peer review by experienced researchers in your field

- rapid publication on acceptance

- support for research data, including large and complex data types

- gold Open Access which fosters wider collaboration and increased citations

- maximum visibility for your research: over $100 \mathrm{M}$ website views per year

At $\mathrm{BMC}$, research is always in progress.

Learn more biomedcentral.com/submissions 